\title{
John Maxwell Brown MBBS, FRACP
}

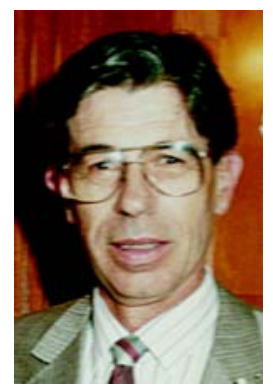

JOHN BROWN was born on 5 August 1934 in

Meadowbank, New South Wales. He lost both parents early in his teenage years and was then raised by his aunt, Doris Johnson. Despite these setbacks, he attended Fort Street Boys' High and subsequently studied medicine at the University of Sydney.

On graduating in 1957, he entered the emerging specialty of paediatrics. While training at the Royal Alexandra Hospital for Children (RAHC), he met a young teacher, Rosemary Wilson, at a church camp, and they married in 1960.

Around this time, John developed an interest in respiratory medicine and, specifically, the management of cystic fibrosis (CF). In the 1960s, the condition carried a life expectancy of 5 years. John was head of the CF clinic at RAHC from 1966 until 1995, during which time management of the condition greatly improved. Now, most children with CF can be expected to live to their 30s.

A particular innovation that greatly improved the quality of life and life expectancy of CF patients was the introduction of multidisciplinary management teams, of which John was a strong and early proponent. John's CF team conducted a regular clinic at the Mount Druitt
Polyclinic, which predated Mount Druitt Hospital. The doctors, nurses, physiotherapists and dietitians would pile into a minibus driven by John and head west each month. A slightly less popular aspect of these trips was John's insistence on a team-building stop at Red Rooster.

John ran busy private practices at Camperdown and Ryde. He visited Nowra once a month in the days before the town gained its own paediatricians. A highly regarded clinician, John was always available for his long-term patients. There was rarely a family dinner that was not interrupted by a phone call from a registrar or an anxious parent.

In retirement, John and Rosemary became keen Scottish country dancers, conducted microscopy courses, collected and sold antiques, and travelled extensively. They were by far the oldest candidates in Japanese at the NSW Higher School Certificate examinations in 2010.

John died of bladder cancer and ischaemic heart disease on 23 May 2012. He is survived by his sister Jeanette, his sons Bevan, Matthew, Lachlan and Martin, and eight grandchildren.

Lachlan T Brown doi: 10.5694/mjal2.10920 